THE INTERNATIONAL

REVIEW OF RESEARCH IN

OPEN AND DISTANCE LEARNING

\title{
Teaching Time Investment: Does Online Really Take More Time than Face-to-Face?
}
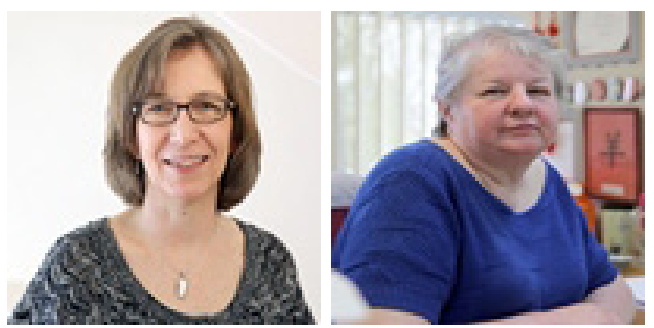

Rebecca Van de Vord and Korolyn Pogue Washington State University, USA

\section{Abstract}

Enrollments in online programs are growing, increasing demand for online courses. The perception that teaching online takes more time than teaching face-to-face creates concerns related to faculty workload. To date, the research on teaching time does not provide a clear answer as to the accuracy of this perception. This study was designed to investigate which aspects, if any, are more time consuming for instructors teaching in the online environment. Time logs were kept by four online instructors (eight classes) and six on-campus instructors (six classes) through six weeks of the 15-week semester. Results indicated that, overall, face-to-face teaching required more time per student, but certain aspects of online teaching take considerably more time per student than in the face-to-face classroom.

Keywords: Time; online; teaching

As online delivery of higher education programs has grown over the past decade, researchers have asked, "does it take more time to teach online?" The perception of faculty consistently seems to indicate that it does. This is a critical concern with economic strains negatively impacting faculty numbers in many academic departments, while at the same time demand for online programs is rapidly increasing. Online enrollments are growing at a rate of $10 \%$, considerably greater than the less than $1 \%$ seen in higher education overall (Allen \& Seaman 2011).

The research results are not definitive one way or the other, suggesting more studies are required. In addition, the rapid changes in technology, mainstreaming of online education, and increased user experience will most likely impact the answer to this question. Most 
important is the ability to understand where faculty spend their time in online instruction. This understanding can inform the development of processes and tools that can facilitate greater efficiency in online teaching.

\section{Review of the Literature}

Researchers employed the university libraries' online education database to search for all articles related to the keywords online teaching time, eLearning teaching time, and distance teaching time and captured all articles available. Further investigation was completed through Google Scholar resulting in no additional articles related to the research topic.

Survey and qualitative interview studies consistently suggest that faculty perceive online teaching as far more onerous than in the face-to-face classroom (Bolliger \& Waslik, 2009; Concieção, 2006; Harber \& Mills, 2008; Lee \& Busch, 2005). Concieção (2006) quotes participants as noting the "intense work involved in designing and delivering an online course because of the length of engagement before and during and the depth of engagement during course delivery" (p. 35). Participants in the study indicated they perceived more time was involved with all aspects of teaching an online class.

Results of studies comparing time spent teaching online with that spent teaching face-toface are not as clear as the survey and interview research noted earlier. Some research suggests that time spent is approximately equal (Hislop \& Ellis, 2004). Other results suggest more time is involved in teaching online when time is calculated per student enrollment (Bender, Wood, \& Vredevoogd, 2004; Cavanaugh, 2005; Hislop, 2001; Spector, 2005; Tomei, 2006; Worley \& Tesdell, 2009). Yet others indicate the time to teach online is actually less than face-to-face (DiBiase, 2000; McKenney, Peffley, \& Teolis, 2010). On the surface these studies provide very conflicting results. It is important, then, to review the prior work more carefully.

Bender et al. (2004) compared a single face-to-face course, with 111 enrolled students and 38 teaching assistants, to an online version with 18 students and five teaching assistants. The online version was a new course and the students and teaching assistants associated with this version were new to the online environment. According to the findings, instruction time was approximately equivalent, but the time required for grading and email communication for the online course was significantly greater than required for the face-to-face version. The time recorded for the online course, however, included training time for the teaching assistants as well as time for the instructors and two teaching assistants to travel to the distance location to sort through technology problems. Additionally, the authors note that the grading was more time consuming in the online course because "lack of a computerized grading process in the distance course resulted in more work" (p. 110). The classroom course was able to "utilize university facilities to electronically grade assignments and e-mail students, the instructor assumed this responsibility in the distance course" (p. 110). In other words, conditions for grading were not equivalent. Furthermore, the fact that the students and teaching assistants were new to the online environment created a variety of 
time-consuming issues that did not relate to actual instruction.

In a similar study, Cavanaugh (2005) logged the time required to teach an economics course, comparing an online version with 15 students to the face-to-face version with 40 students. Initial design time for the online course was not included, but updating the online portion of the course, contacting the students to get them started, and final tasks related to miscellaneous administrative-type duties performed at the end of the course for the online version only were counted. There is no indication that grading time for the two courses was examined in the study. Overall, time per student for the online version was greater.

The Hislop (2001) study involved four pairs of course sections taught in the same or successive terms by the same instructor. The pairs included three different courses and three different instructors. This study included only time expended during delivery of the course, excluding course preparation time. In this study, two of the online versions took more time, and two took less time to deliver than the face-to-face versions. In all cases, however, the online courses took more time per student, but in three of the four cases the differences were "not all that large" (p. 26). Enrollment numbers for each of the courses is not mentioned in the article. Of interest, the authors note that online instructors logged time spent on the course more days per week than for the face-to-face version suggesting that "online courses clearly have a different rhythm to them" (p. 26).

Spector (2005) focused on communication methods, comparing different forms of e-collaboration and the effects on time demands placed on teachers and students in three online and one face-to-face course. Results suggested that email is less efficient than threaded discussions or chat sessions for instructors. The instructor teaching the one course in both the online and face-to-face environments spent significantly more time in the online course. In addition, the authors note that two instructors teaching online reported they spent about twice as much time in their online course as face-to-face "but no data were collected to corroborate these reports" (p. 17). The conclusion was based on instructor perceptions rather than the time logs.

Tomei (2006) compared a traditional evening class, 11 students enrolled, with a distance course of the same content and also with 11 students, two with prior online experience. Distance students communicated with the instructor through "weekly e-mails, end of session posts, and periodic online chat sessions" (p. 534). The author found that instructing via discussion, e-mail, and chat increased time demands of the online course a minimum of $14 \%$.

Worley and Tesdell (2009) each taught an online version and a face-to-face version of the same course at their respective universities. The authors kept "a time log of every minute we spent teaching" (p. 141). Enrollment of the online courses was 30 and 26, and the faceto-face 43 in each case. The courses had previously been taught in both online and face-toface versions, and the instructors were experienced in both delivery venues. Time spent in each of the following categories was recorded: tool training time and effort, preparation time and effort, teaching time and effort, and technical time and effort. Results indicate 
approximately 20\% more time was spent per student in the online course. Significant time differences were found, with time required for online being greater in time spent setting up the online environment, record keeping, and miscellaneous. Significantly more time was spent in the face-to-face class than in the comparable synchronous chat held for the online course. The authors' conclusions echo those of Cavanaugh, finding that overall time spent on the online course was not greater, but that time per student is greater.

Similar to an earlier study, the Hislop and Ellis (2004) study employed seven pairs of graduate classes. Class size for the online versions averaged 19.3 and for the face-to-face 26. As with most of the prior studies noted in this review, the instructors were experienced in both the face-to-face and online environments and focused on time required to deliver the course, excluding development time. The authors conclude that when class size is taken into account, the average time spent per student was "nearly equivalent for online and faceto-face" (p. 15). They note, however, that time spent in the online course was more fragmented and involved a greater number of days, suggesting that teaching online requires more effort, but not necessarily more time. Further, according to the authors, "the data appear to be internally consistent, where different instructors expended similar efforts for the same courses and the same instructors exhibited the same effort pattern across different courses" (p. 29).

Finally, at least two research studies suggest that time spent teaching online is less than teaching face-to-face. McKenney and colleagues (2010) compared a completely online course with 47 students in two sections to two Web-facilitated face-to-face sections with a total of 192 students, finding the fully online sections take less time. Only actual instruction time was measured. Teaching included "lecturing, releasing modules, or posting assignments" (p. 247). Initial course preparation was not included, but ongoing preparation, such as reviewing modules or copying handouts, was included. It appears that communication time with individual students was not considered to be instruction time. Instead, the authors analyzed the number of student contacts, finding them to be significantly greater in the fully online sections, as would be expected. In an online course it is this individual communication that in part replaces the classroom sessions.

DiBiase (2000) conducted a comparison of two geography courses. The online versions (four sections) were offered to adult professionals, enrollment averaging 18 per section. The two face-to-face sections were offered on campus to college undergraduate students with a total enrollment of 223. During the period of the study, the instructor and his teaching assistants recorded any teaching episode lasting longer than five minutes. Consistent with most of the other studies noted here, course development time was not included. The findings indicated that time per student in the online classroom was less than time per student required in the face-to-face classroom. Similar to the Hislop and Ellis (2004) findings, the author notes that the number of days during which the instructor engaged in activities related to the online classroom was greater for the online course (5) than the face-to-face course (4).

A multitude of factors influence the amount of instructor time required to teach either 
a face-to-face or an online course. Class sizes in these studies were consistently smaller for the online versions than the face-to-face versions. Exploring the scalability of distance learning courses, DiBiase and Rademacher (2005) note that as the course enrollment increased by a factor of 2.7, time required by the course increased by a factor of 2.5 . In other words, as enrollment increases teaching time does not also increase at the same rate, suggesting that smaller courses require more time per student making larger courses more efficient to teach. This would be true in the face-to-face environment as well with required hours of class meetings held constant despite enrollment size.

Second, DiBiase (2000) argues that "the amount of effort required to teach a distance course may be inversely proportional to the effort invested in instructional design and development" (p. 19). The studies noted above do not indicate to what extent online instructional design expertise was employed.

Third, some administrative items noted in the studies above are handled differently for online and on-campus courses, or were in the early days of online delivery. As online instruction becomes more a part of the norm, the instructor may spend less time explaining to students how to access their course spaces and other technical issues, for example. In addition, universities are developing systems for orienting online students and providing other services which more closely replicate the on-campus experience. As we see these changes occur, how is online teaching time impacted?

\section{Method}

There is great variety in the way that online courses are developed and delivered across institutions of higher education. At the university where the current study was conducted, there is a center which supports the development and delivery of online courses, including student and faculty support services. All courses are developed by faculty in conjunction with an instructional designer and all employ the same template, creating consistent navigation across all courses.

Initially a pilot group of nine online instructors was asked to maintain a daily time log, recording start and end times for all activities related to the course for three of the final four weeks of the semester. The instructors were selected solely on their willingness to participate. It was thought that this information then would provide a foundation for developing categories of instructional processes for use with a greater number of instructors in the following semester. By starting without preset categories researchers hoped not to bias the reporting but instead explore the categories that emerged. The group also agreed to continue the record-keeping the following semester and suggested that maintaining data from seven weeks would provide a sound representation of the full semester's work (15 weeks plus final exams.)

Of the nine instructors, six completed the original task. From the time logs each maintained, spreadsheets were created to categorize the time spent related to teaching. These categories included interacting with students, evaluating students' work, lecture prepara- 
tion/course modifications, recording grades, and addressing technical issues. The category interacting with students included email and phone. The category evaluating students' work included evaluating exams, assignments, and discussion board posts.

The following semester the instructors were contacted and most all indicated they would not be able to participate a second semester, in some cases because teaching assignments had changed. Thirty more instructors, some teaching online and others in the face-to-face environment with the goal of providing a contrast, were contacted via email, based on a perception that they might be willing to participate. The researchers for this current study were not participants as was common in much of the previous research, potentially minimizing bias in the gathering of the data. In the end, four online instructors, teaching eight classes, and six on-campus instructors, teaching six classes, recorded data for six weeks on the spreadsheet provided by the researchers and using categories that had emerged from the pilot study. Since the face-to-face environment was being added at this point, time interacting with students before or after class was added to the interacting with students category.

Table 1

Courses in Study with Enrollments

\begin{tabular}{|c|c|c|c|}
\hline \multicolumn{2}{|l|}{ Face-to-face courses } & \multicolumn{2}{|l|}{ Online courses } \\
\hline Course & Enrollment & Course & Enrollment \\
\hline Molecular Biosciences & 24 & Physics & 30 \\
\hline General Education & 37 & $\begin{array}{l}\text { General Educa- } \\
\text { tion }\end{array}$ & 69 \\
\hline Teaching \& Learning & 37 & Philosophy * & 36 \\
\hline Marketing & 34 & Philosophy * & 52 \\
\hline Psychology & 137 & Philosophy * & 60 \\
\hline \multirow[t]{3}{*}{ Psychology } & 64 & $\begin{array}{l}\text { Human Develop- } \\
\text { ment** }\end{array}$ & 59 \\
\hline & & $\begin{array}{l}\text { Human Develop- } \\
\text { ment** }\end{array}$ & 49 \\
\hline & & $\begin{array}{l}\text { Human Develop- } \\
\text { ment** }\end{array}$ & 66 \\
\hline
\end{tabular}

*The three philosophy courses were taught by the same instructor. The instructor recorded time for all courses in combination, so in the analysis these three courses were treated as one. ${ }^{* *}$ The three human development courses were taught by the same instructor. The instructor recorded time for all courses in combination, so in the analysis these three courses were treated as one.

For the online courses, none of the instructors or courses were new to the online environment. All online courses had been developed and taught previous semesters by the same instructors so development time was not included in this study. All face-to-face courses had 
also been taught by the instructors before with the exception of a face-to-face psychology course which was being taught by the instructor for the first time and therefore took more effort than would be typical. A full semester is 15 weeks plus a final exam week during which regular classes are not held and only final exams take place. Instructors were asked to record their time for weeks 5, 6, 9, 10, and 14 through submission of final grades. It was perceived after the feedback from the pilot that instructors would not be willing to keep track for the full 16-week semester. The weeks chosen to provide a sample representative of a semester's work were identified as generally heavy grading weeks by the researchers and instructors involved in the pilot. In fact, not all instructors maintained accurate data through the seven weeks of the study and those teaching multiple courses had difficulty separating their data accordingly.

Therefore, the following adjustments were made: the teaching and learning, human development, and marketing courses did not have final tests and were thus completed in week 15 . For these five courses, weeks 14 and 15 were counted as the final two weeks of work of the semester. The online general education course was missing data for weeks 14 and 15 . It was determined that with two courses completing early and one missing data, week 14 would be removed from all of the other courses. None of those courses with data in that week had anything remarkable so removing the data did not change their outcome. Overall, six weeks of data, then, instead of seven, were used to assess differences between online and on-campus teaching time. Additionally, the three philosophy and the three human development courses were taught by the same instructor. In both instances the instructors recorded the combined time spent teaching all three courses, rather than by individual course.

For this study, rather than using pairs of courses, that is the same course taught face-toface and online, or a single instructor teaching both online and face-to-face, a selection of courses across disciplines was thought to provide a broader perspective than has been discussed in previous research. The goal was to provide data across a range of fields, moving beyond the limits of single instructors or disciplines. The minutes spent teaching onsite in the classroom was included in the grand total and as a component of student interaction. No initial course development time for either online or face-to-face courses was included in the study, consistent with prior research (Cavanaugh, 2005; Hislop \& Ellis, 2004; McKenney, Peffley, \& Teolis, 2010).

\section{Results}

Total teaching time, per week, per student in the face-to-face course ranged from 3.83 minutes to 36.32 minutes, with a mean of 14.98 and a median of 13.88 . In the online courses the range was 11.21 minutes to 16.72 , with a mean of 12.7 and a median of 12.32. The range in the data for face-to-face categories was large when compared to the range in online courses, making the median rather than mean a better comparison between the two delivery systems. 
Table 2

Time Log Categories

\begin{tabular}{lcccccc}
\hline & \multicolumn{2}{c}{ Face-to-face } & & \multicolumn{2}{c}{ Online } \\
\cline { 2 - 3 } \cline { 6 - 7 } Category: Minutes per student & Median & Mean & & Median & Mean \\
\hline Interacting with Students & 31.70 & 44.17 & & 20.42 & 21.97 \\
Evaluating Student's Work & 14.77 & 22.49 & & 48.72 & 47.84 \\
Lecture Prep/ Modification to Course & 12.60 & 21.10 & & 0.00 & 0.61 \\
Recording Grades & 2.25 & 2.03 & & 4.82 & 4.46 \\
Technical Issues & 0.00 & 0.11 & & 1.21 & 0.86 \\
Grand Total less Technical Issues and & & & & & \\
Lecture Prep/Mod to Course & 48.72 & 68.69 & & 73.78 & 74.27 \\
\hline Average per week & 13.88 & 14.98 & & 12.32 & 12.70 \\
\hline
\end{tabular}

How much time an instructor is present in the face-to-face classroom is very clear. All of the classes in the study were three credits and required three 50-minute classes per week, or 150 minutes for five weeks, totaling 750 minutes, as no classes are held during finals week (week 16). Depending on class size, minutes per student expended in the classroom varied from 5.47-31.25 (median 15.99). In addition, face-to-face instructors spent 7.888.82 minutes per student interacting outside of the scheduled class time, which included reading email, answering the phone, talking with students before or after class, and office hours. Office hours were recorded only if there was student interaction during the scheduled hours. Together then, face-to-face instructors spent 13.35-100.07 minutes teaching and interacting with students with a median of 31.7 minutes per student.

In contrast, online courses did not include synchronous lecture time so instructors spent no scheduled time during the week in a classroom, but instead interacted with students via asynchronous technology tools. The range for interacting with students was 16.67-37.67, with a median of 20.42. It is of interest to note that, even with the more rigid schedule of the face-to-face course, the range in the online courses was considerably narrower than for the face-to-face courses.

In addition to interacting with students, a substantial amount of teaching time is invested by instructors evaluating student work. For the face-to-face classroom this includes grading assignments and exams and providing feedback. On average, the face-to-face instructors expended 5 to 49.41 minutes per student evaluating course work with a median of 14.77. In comparison, online instructors invested 38 to 49.36 minutes per student grading with a median of 48.72 , more than three times as much as in the face-to-face courses. Similar to evaluating online student work, face-to-face courses involve grading assignments and assessments, but online instructors also evaluate online discussion postings in many courses. While evaluating course work for online courses clearly required more time than 
in the face-to-face classroom, there was less variation in the range than in the face-to-face courses.

This study also examined the amount of time instructors spent modifying their courses while teaching them. For face-to-face courses, ongoing lecture preparation required a median of 12.6 minutes per student compared with .oo minutes per student in online course modification because the preparation for the online course is completed before the first day of the semester in most cases.

Lastly, time required by the instructor for addressing technical support issues was minimal in the face-to-face course at .oo median minutes/student and greater in the online course at an average of 1.21 minutes per student, as would be expected.

\section{Discussion}

The perception amongst the academic community is that it takes more time to teach an online class than one face-to-face. Researchers have been investigating this question and so far have come to no clear conclusions. At the same time, the technology has been advancing, along with increased mainstreaming of online education which brings with it more experience and better institutional support structures. The current study explored time records kept by online and on-campus instructors for six weeks during a 16-week semester. According to the data, overall the time spent by face-to-face instructors was greater (median 14.98) than online (median 12.70), suggesting, on the surface, more time was spent teaching face-to-face. This surface level finding, however, does not tell the whole story.

Comparisons such as this are difficult. Comparing one individual course to another, it is difficult at best to account for differences between instructors, content, and students. A course which one semester seems fairly easy to teach can the next semester be much more time consuming due to the particular group of students. Comparing face-to-face and online courses increases the challenge because there are considerable differences between the environments, which are in many ways like comparing apples to oranges. For example, there is the more traditional process of creating course materials "as you go" in the face-to-face environment versus creating the online course in its entirety prior to delivery. Further, there are variations across universities in the processes related to development and delivery of online courses. Since there is a perception that online courses take more time, however, it is important to continue to investigate and understand the workload differences inherent in the two environments.

To put the data of this study in perspective one must understand the online teaching environment at the university where the research took place. A center has been established to work with departments to deliver all online courses. The center provides student services including advising, instructional design, technology, and faculty support. These support services include 24/7 technical support for both students and instructors. Further, the one-to-one instructional design support provided during course development, training of instructors, assistance in the ongoing updating and maintenance of courses, and the appli- 
cation of a consistent course template are all intended to minimize student and instructor support needs and workload demands.

Lecture preparation was included in the data recorded. Since online courses are set up prior to the first day of class, there is no equivalent task for the online instructor during the period of delivery. It was thought that lecture preparation time in the face-to-face course might be offset by technical support demands of the online course. Findings from other studies have suggested that the online instructor spends significant time providing student technical support (e.g., Bender, Wood, \& Vredegood, 2004; Lee \& Busch, 2005; Santilli \& Beck, 2005 ). Technical support time (1.21 minutes per student), however, was considerably less than the lecture preparation time (12.6 minutes per student) required in the face-to-face course, perhaps owing to the $24 / 7$ technical support described above, suggesting one does not offset the other. If lecture preparation and technical support were both eliminated from the data, face-to-face instructors would have invested less time overall during the period of delivery than online instructors in this study. Subtracting out the lecture preparation and technical support time, face-to-face instructors invested a median time of 11.45 minutes per week (mean 8.12) compared to the online median time of 12.30 minutes per week (mean 12.38), suggesting that these online instructors are spending about a minute per week per student more in their online course.

The aspects of teaching that include interaction with students, whether in the physical or online classroom, before or after class, or via email, phone or during office hours is not more time consuming in the online environment than the face-to-face environment, according to the results of this study. In fact, more time was recorded as interacting per student in the face-to-face environment. In part, this may be due to the fact that no matter how many students enroll in a face-to-face course, the instructor must spend the requisite three hours per week (for a 3-credit class) in the classroom. An online course does not have similar requirements as course materials are preprepared and available to students, rather than being presented in a "Carnegie Hour" format. On the other hand, one of the previous findings related to teaching online is that the communication style of the online environment causes instructors to feel that they are working 24/7 (Concieção, 2006; DiBiase, 2000; Hislop \& Ellis, 2004). It is possible that this communication style is beginning to infiltrate the faceto-face environment as well, increasing the amount of time or frequency that instructors spend interacting with students who use email instead of office hours for communication.

According to the data in this study, evaluating student work is much more time intensive for online instructors, including the uploading of grades. Further research is required to determine exactly where this time is being spent, but it is likely due in large part to online courses depending on text-based discussion, which requires thorough reading not only to evaluate student learning, but to facilitate that learning as well. In fact, instructors participating in this study commented on the extensive time invested in grading. One instructor stated, "Grading these 8-10 page papers also takes a very long time. Trying to read and grade these papers in a timely manner and keep up with weekly posts is where most of my time goes." 
A second instructor commented,

I think my biggest surprise is that it takes longer to grade papers on the computer than it does with a pile of them in hard copy form in front of you. Also giving feedback is much more time consuming, because it must be done for every student individually, whereas in a classroom an instructor may give general feedback to the whole class at the same time. Thirdly, as papers are graded students ask questions, which is an excellent thing, but more students actually ask for more feedback than in the classroom. This again takes more time.

These comments suggest that strategies are needed to assist instructors in online grading and efficiently facilitating and evaluating discussion. These strategies can range from randomized grading of a select number of discussion postings, implementing peer review of fellow students' postings, and exploring posting of audio discussion and audio feedback which might be less time consuming to create and critique. Furthermore, personal experience with learning management systems leads to the observation that uploading and downloading of documents to grade and then return to the student is less efficient than the traditional handing in and handing back of assignments and assessments, as also noted in the second quote above. Technology developers need to investigate more efficient grading processes. Lastly, ensuring that instructors have the appropriate training with the learning management tools is critical.

There appears to be a larger variation in the time commitment of face-to-face instructors than online instructors. The total minutes per week per student in the face-to-face environment ranged from 3.83-36.32 while in the online environment the range was 11.01-16.72. This is possibly due to a larger variation in enrollment, although there is not a clear correlation between enrollment numbers and time spent teaching in either environment. This finding may suggest that the similar structure of these online courses minimizes the variation, and perhaps flexibility, of online instructors. This may relate to the use of a consistent template and systematic development of the online courses that were a part of this study. In addition, as mentioned previously, the university maintains a center which supports these online instructors and their students, possibly relieving them of greater time requirements that teaching in other online programs might demand

As in this study, most research has focused on time spent during course delivery. Future research should explore the time required to prepare the online course versus creating a new face-to-face course. For both environments, development of a new course takes time.

This research has a number of limitations. In the field of education it is very difficult to conduct controlled experiments. Students self-select into courses and course environments. Of greater concern in this study, researchers were dependent on the instructors keeping accurate, detailed records over a period of time. Researchers were not able to offer incentives to participate in this study so had to rely on the generosity of the faculty who volunteered. 
To make this task somewhat less onerous, and potentially increase the accuracy and number of participants, the number of weeks instructors were asked to keep data was limited to seven (with six completed). This was a tradeoff, however, in that it is then only a sample of time across the semester. It would be worthwhile, based on these data, to further investigate with a full semester of data. It is worth noting that the two most similar courses, the general education face-to-face and online course, followed the same pattern of results as has been reported for the groups of courses on the whole, suggesting external validity of the data. Finally, the study did not compare exact pairs of courses, online and face-to-face, taught by the same instructor as many courses at this university are taught either online or face-to-face but not necessarily both.

The intent of this study was to provide a broader picture and to move beyond factors related solely to individual instructors or individual courses. This study was able to include more of a cross section of instructors and courses than previous research. The pilot study provided information that enabled the targeting of specific activities where instructors spend significant time in both course delivery formats. Our findings conclude that interaction time with students is greater in the face-to-face courses while evaluating students and their work is greater in the online courses. The importance of these data is not whether time demand, overall, is greater in one environment or the other but where and how that time is spent, which will point to possible strategies for supporting instructors teaching online.

First, the data suggest that online instructors are spending three times more time than faceto-face instructors evaluating student work. This is a difficult task and suggests that teaching online is perhaps more difficult, rather than more time consuming, than teaching face-toface. The greater investment of face-to-face teachers is time in the classroom lecturing or facilitating. These are activities with which face-to-face instructors are very comfortable and are not likely to define as challenging. Considering the findings of the current study, combined with the research of Hislop and colleagues, that teaching online is more demanding in frequency of interaction, it is no surprise that instructors are concerned when asked to teach online. It behooves those who are looking to grow their online programs to invest in technological solutions that will ease the burden on online faculty.

Second, there was far less variation in the amount of time spent teaching online than in the face-to-face environment, yet it seems that one could assume that instructors and course content vary as much online. This may suggest that the learning management system, the structure of the online courses, or other unidentified factors play a role in determining amount of time spent teaching online. This finding requires further investigation to determine how this information can best serve online instructors in managing their teaching time.

Ongoing research is required to capture the continually changing environment of technology in course delivery, for both online and face-to-face courses, and how these changes effect faculty teaching time in the classroom. 


\section{Acknowledgements}

Kathryn Baldwin, Linda Cook, Ken Faunce, Mary Garcia, Lydia Gerber, Sally Horton, Ioannis Kareklas, Janet Kendall, Richard Kouzes, Phil Longstreet, Norah McCabe, Valeria Pietz, Jeannie Pittman, Nori Porter, Brigit Schneider, Carole-Anne Seeley, Rob Snyder, Samantha Swindell, Steve Ullrich. 


\section{References}

Allen, E., \& Seaman, J. (2011). Going the distance: Online education in the United States, 2011. Babson Survey Research Group. Retrieved from http://sloanconsortium.org/publications/survey/going distance 2011

Bender, D. M., Wood, J.B., \& Vredevoogd, J. D. (2004). Teaching time: Distance education versus classroom instruction. The American Journal of Distance Education, 18(2), 103-114.

Bolliger, D., \& Waslik, O. (2009). Factors influencing faculty satisfaction with online teaching and learning in higher education. Distance Education, 30, 103-116.

Cavanaugh, J., (2005). Teaching online-A time comparison. Online Journal of Distance Learning Administration Content, 8(1). Retrieved from http://www.westga. edu/ distance/ojdla/spring 81/cavanaugh81.htm.

Concieção, S. C. (2006). Faculty lived experiences in the online environment. Adult Education Quarterly, 5, 26-45.

DiBiase, D. (2000). Is distance teaching more work or less work? The American Journal of Distance Education, 14(3), 6-20.

DiBiase, D., \& Rademacher, H. (2005). Scaling up: Faculty workload, class size and student satisfaction in a distance learning course on geographic information science. Journal of Geography in Higher Education, 29, 139-158.

Harber, J., \& Mills, M. (2008). Perceptions of barriers concerning effective online teaching and policies: Florida Community College Faculty. Community College Journal of Research and Practice, 3, 266-283.

Hislop, G. (2001). Does teaching online take more time? Paper presented at $31^{\text {st }}$ ASEE/ IEEE Frontiers in Education Conference, October 10-13, Reno, NV.

Hislop, G., \& Ellis, H. J. C. (2004). A study of faculty effort in online teaching. Internet and Higher Education, 7, 15- 31.

Lee, J. A., \& Busch, P. E. (2005). Factors related to instructors' willingness to participate in distance education. Journal of Education Research, 99(2), 109-115.

Lonn, S., \& Teasley, S. D. (2009). Saving time or innovating practice: Investigating perceptions and uses of learning management systems. Computers \& Education, 53, 686-694.

McKenney, C., Peffley, E., \& Teolis, I. (2010). Comparison of time investment in common teaching practices among three instructional methods. Teaching Methods, 20, 245-249. 
Mital, M. (2007). Integrating technology into the teaching-learning transaction: Pedagogical and technological perceptions of management faculty. International Journal of Educational Development Using Information Communication Technology, 3(1). Retrieved from http://vnweb.hwwilsonweb.com/hww/results/results single ftPES.jhtml.

Santilli, S., \& Beck, V. (2005). Graduate faculty perceptions of online teaching. The Quarterly Review of Distance Education, 6(2), 155-160.

Spector, M. (2005). Time demands in online instruction. Distance Education, 26, 5-27.

Tomei, L. A., (2006). The impact of online teaching on faculty load: Computing the ideal class size for online courses. Journal of Technology and Teacher Education, 14(3), 531-541.

Worley, W., \& Tesdell, L. (2009). Instructor time and effort in online and face-to-face teaching: Lessons learned. IEEE Transactions on Professional Communication, $52,138-151$.

Wang, M., MacArthur, D. A., \& Crosby, B. (2003). A descriptive study of community college teachers' attitudes toward online learning. Tech Trends, 47(5), 28-31.

\section{Athabasca University}

(2) (1) 